\title{
Fornix and Hippocampal Atrophy in Traumatic Brain Injury
}

\author{
David F. Tate and Erin D. Bigler ${ }^{1}$ \\ Department of Psychology, Brigham Young University, Provo, Utah 84602, USA
}

\begin{abstract}
This study compared a fornix cross-sectional-area measurement and hippocampal volume in 86 traumatic brain injury (TBI) subjects with 46 normal controls. The TBI group showed a significant reduction in fornix area and hippocampal volume. It was also shown that initial injury severity was related to the degree of atrophy in both structures. Although fornix size and hippocampal volume correlated, such a modest correlation between these two structures suggests differential and potentially independent mechanisms of injury. The General Memory Index score from the Wechsler Memory Scale-Revised was shown to be significantly correlated with hippocampal volume following TBI.
\end{abstract}

When the neuroanatomical basis of memory and learning is discussed, reference typically is made to temporal lobe structures, particularly limbic system structures (D'Esposito et al. 1995; Aggleton 1999). Disorders of memory and learning are common in traumatic brain injury (TBI) (Dixon et al. 1993; Bigler et al. 1996), and although the neuroanatomic basis for disordered memory in TBI has not been fully addressed, the limbic system is implicated. There are several mechanisms whereby TBI may result in pathological changes in the temporal lobes. For example, with high speed impact and/or acceleration-deceleration injuries, the medial temporal lobe is particularly vulnerable to mechanical deformation and contusion because of its location in the middle cranial fossa (Levin et al. 1982; Adams et al. 1985; Sweeney 1992; Gean 1994). In addition to these tissue derangements resulting from direct-impact forces, perturbation of temporal lobe limbic structures such as the hippocampus results in excitotoxic reactions leading to further cellular damage or death (Faden et al. 1989; Nilsson et al. 1990; Palmer et al. 1993; Fujita et al. 1996; White and Reynolds 1996; Shah et al. 1997). Acutely, each of these pathological reactions (either individually or in combination) may result in secondary localized edematous and vascular changes that may add to the damage (Gean 1994). Furthermore, postacutely, hippocampal deafferentation and/or deefferentation may result in transneuronal degeneration, causing hippocampal cell death. Thus, in theory, TBI-related hippocampal damage may be a combination of direct injury, excitotoxic neuropathological changes, vascular compromise, metabolic changes, and/or transneuronal degeneration (Gennarelli et al. 1998).

The fornix represents the major aspect of hippocampal output, comprised of axonal projections from the hippocampus to the mamillary bodies (MB) (Brodal 1981; Carpen-

\footnotetext{
${ }^{1}$ Corresponding author.

E-MAIL erin_bigler@byu.edu; FAX (801) 378-7862.

Article and publication are at www.learnmem.org/cgi/doi/ $10.1101 / \mathrm{lm} .33000$.
}

ter and Sutin 1983). This delicate white-matter pathway emerges from the posterior portion of the hippocampus first curving upward, projecting anteriorally, and then descending downward, as the column of the fornix, to the MB. Although not all of the axons of the fornix have their origin in the hippocampus, the majority of the fibers do and it is considered the limbic structure that interconnects the hippocampus with the MB and, hence, the rest of the limbic system (Brodal 1981).

In separate independent studies, we have shown previously that trauma results in hippocampal (Bigler et al. 1996, 1997) as well as fornix atrophy (Gale et al. 1993). However, none of these investigations examined the relationship between hippocampal atrophy and fornix atrophy. At an anatomical level, it seems reasonable to assume that atrophy of the hippocampus would, in some fashion, result in proportional atrophy of the fornix, because the whitematter tracts of the fornix originate mainly from hippocampal neurons. On the other hand, the hippocampus is predominantly a gray-matter structure housed in the mesial temporal lobe, whereas approximately half the length of the fornix, a white-matter structure, is suspended in ventricular space as it makes its arch from the alveus to the MB. Because of the length of the axons that comprise the fornix, these long-coursing, suspended white-matter fiber tracts may be more susceptible to shear, strain, or tensile effects. Accordingly, pathology associated with head injury may be partly independent for these two structures because of differences in the mechanism of injury to two different tissue types.

Lastly, because memory disorders accompany damage to either the hippocampus or fornix (D'Esposito et al. 1995; Aggleton 1999), what is the relationship between atrophy of these limbic structures and memory in TBI? To address these issues, hippocampal volume and fornix cross-sectional area were examined in TBI patients with varying degrees of injury severity. The relationship between these atrophic changes and memory was further studied using the

LEARNING \& MEMORY 7:442-446 @ 2000 by Cold Spring Harbor Laboratory Press ISSN1072-0502/00 \$5.00

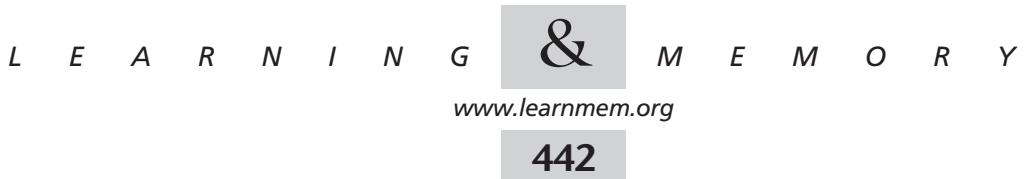


General Memory Index (GMI) score on the Wechsler Memory Scale-Revised (WMS-R) (Wechsler 1987).

\section{RESULTS}

Means and standard deviations for cross-sectional fornix size and hippocampal volumes in both normal control and TBI subjects are summarized in Table 1. Clearly there are significant differences between controls and TBI subjects for both the hippocampus $\left(\mathrm{F}_{(1,131)}=19.03, P<.001\right)$ and fornix $\left(\mathrm{F}_{(1,130)}=267.84, P<.001\right)$ measurements. Interestingly, in TBI subjects, hippocampal volume and fornix cross-sectional area were significantly correlated $(r=0.33$, $P=0.001)$, whereas hippocampal and fornix areas in normal control subjects were only nominally correlated ( $r=0.17, P=0.27)$.

The influence of injury severity on fornix cross-sectional area and hippocampal volume are summarized in Figure 1 , which demonstrates a significant decrease in fornix area and hippocampal volume with increasing injury severity, even when the factors of age and sex were controlled (Hotelling's T=107.43; $P<0.001$ ). A Scheffe's post hoc analysis demonstrated a significant difference between all groups for the fornix cross-sectional area measure at the 95\% confidence level, whereas only the control group and the most severe group (GCS = 3-8) significantly differed for the hippocampus measures at the same significance level. Both fornix cross-sectional area $(r=.40, P=0.002)$ and hippocampal volume $(r=0.29, P=0.02)$ were significantly correlated with GCS.

Although overall memory performance as measured by the GMI of the WMS-R was not significantly correlated with fornix cross-sectional area $(r=0.23, P=0.09)$, it was significantly correlated with hippocampal volume $(r=0.32$, $P=0.01)$. Furthermore, those subjects in the severe GCS group had GMI scores that were less than the mild-to-moderate GCS group, although these differences were not significant $\left(\mathrm{F}_{(1,85)}=0.89, P=0.35\right)$.

\section{DISCUSSION}

Trauma results in fornix and hippocampal atrophy, with degree of atrophy related to severity of injury. However, the linear relationship between fornix size and hippocampal
GCS and Hippocampal Volume and Fornix Area

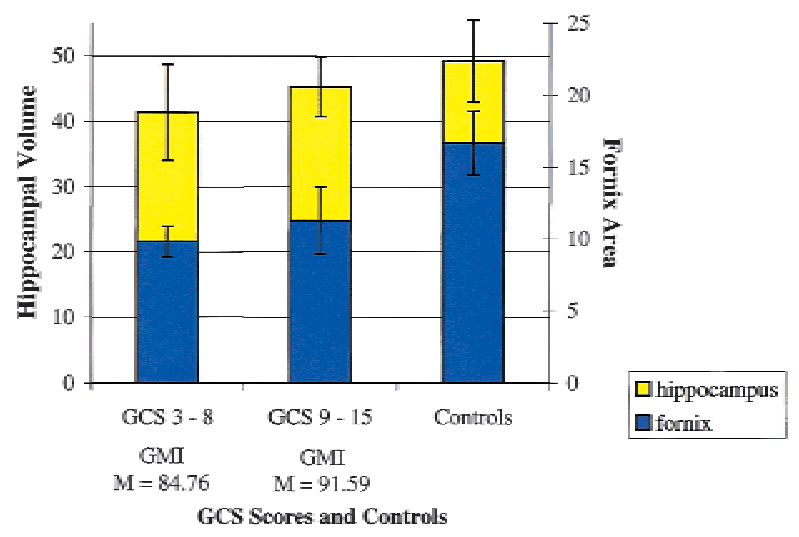

Figure 1 This graph shows both the hippocampal volume and fornix area in millimeters in relation to the Glasgow Coma Scale (GCS) scores (bars indicate S.E. for measures). The mean General Memory Index (GMI) scores are also shown for the two GCS categories.

volume in both normal and TBI subjects is minimal, with only $\sim 11 \%$ of explained variance accounted for by the size of these two structures in TBI patients. Thus, a more atrophic hippocampus does not necessarily predict an atrophic fornix or vice versa. This minimal explained variance between these two structures suggests semi-independence, at least in terms of their size. Accordingly, following brain injury, hippocampal atrophy is related to fornix atrophy, but the lack of more significant correlations between the two structures following injury may implicate different neuropathological processes that result in reduced size of both structures following trauma.

For example, Strich (1956) and, more recently, Blumbergs et al. (1994) found lesions in the fornix but not the hippocampus in a group of autopsied subjects who had sustained a head injury shortly before death. In a fluid-percussion animal study (Pierce et al. 1999), both hippocampal and fornix lesions were demonstrated in only the more severely injured rats. Finally, in a recent temporal lobe epilepsy study (Martin et al. 1999) and in schizophrenic patients (Chance et al. 1999), general independence of for-

Table 1. Descriptive Statistics for Control and TBI Subjects

\begin{tabular}{|c|c|c|c|c|c|c|}
\hline & \multicolumn{3}{|c|}{ Fornix total } & \multicolumn{3}{|c|}{ Hippocampus total } \\
\hline & $n$ & mean & S.D. & $n$ & mean & S.D. \\
\hline Male controls & 31 & 17.20 & 2.33 & 31 & 49.67 & 6.08 \\
\hline Female controls & 15 & 15.66 & 1.69 & 15 & 48.32 & 6.60 \\
\hline Total controls & 46 & 16.69 & 2.23 & 46 & 49.23 & 6.22 \\
\hline Male TBI & 58 & 10.51 & 1.89 & 58 & 44.86 & 5.74 \\
\hline Female TBI & 28 & 10.34 & 2.28 & 28 & 42.67 & 7.68 \\
\hline Total TBI & 86 & 10.45 & 2.01 & 86 & 44.15 & 6.47 \\
\hline
\end{tabular}

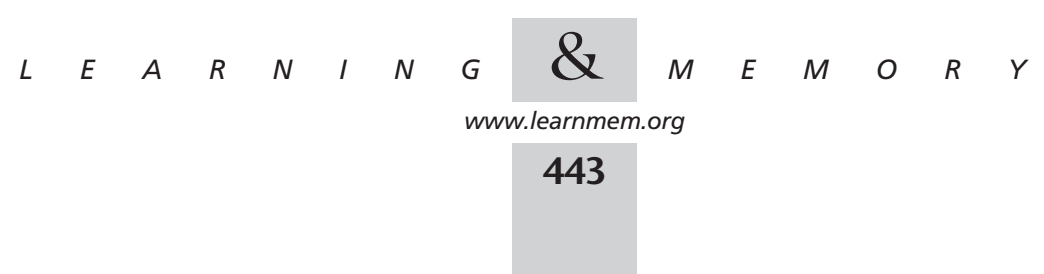


nix size and hippocampus in patients with mesial temporal lobe pathology was demonstrated. As discussed above, the hippocampus proper-as a predominantly gray-matter structure-is probably more vulnerable to the pathophysiological and excitotoxic effects of cerebral trauma. In contrast, the fornix probably is more vulnerable to the tensileshearing action of the long-coursing axons that comprise this white-matter structure. Even though the majority of the axons in the fornix arise from cell bodies in the hippocampus, physiological and vulnerability differences to mechanical deformation create a circumstance in which the degree of trauma-induced atrophy in each structure appears to be partially independent of the other, despite their anatomical relationship.

TBI subjects with the most severe injury displayed, as expected, the most significant impairment in memory performance on the WMS-R (Fig. 1). Despite the reduced memory performance in the more severely injured, the correlation between fornix size and memory was weak $(r=0.23)$, as was hippocampal volume and memory $(r=0.32)$. Although the role of the hippocampus in memory is well established (Squire et al. 1991), it is an oversimplification to state that memory disorders in TBI are specific to hippocampal damage and are the sole neuroanatomical factor disrupting memory function (Bigler et al. 1996). Studies that have examined hippocampal volume and memory in patients with varied etiologies (Lencz et al. 1992; Bigler et al. 1997; Heun et al. 1997; Stout et al. 1999) have found only modest relationships between hippocam-

Normal

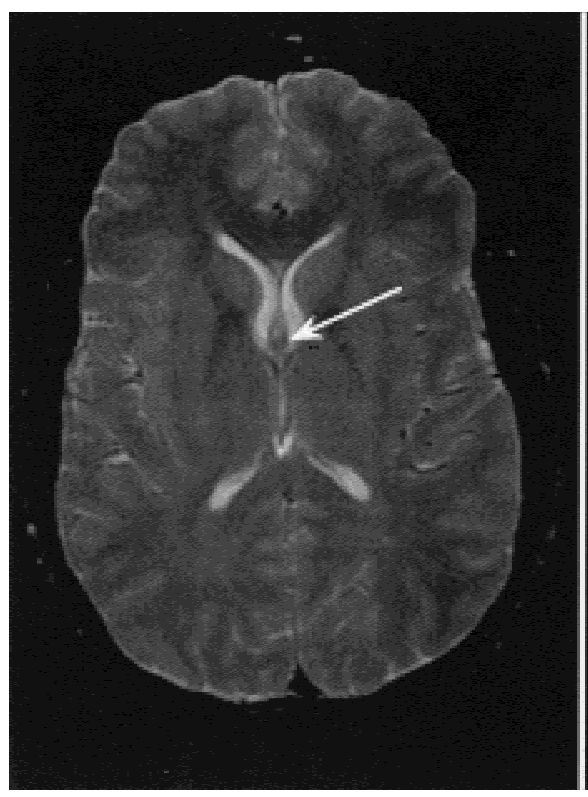

Figure 2 Axial views of the column of the fornix in a normal control subject (left) and a traumatic brain injury (TBI) subject (right) indicating the level for obtaining a cross-sectional fornix area. Note the global atrophy in the TBI image. pal size and memory performance. Likewise, the injury in TBI is a disseminated injury, affecting diverse neural structures outside the limbic system (Gale et al. 1995; Blatter et al. 1997). Thus, memory disruption in TBI is probably a combination of specific, yet independent, injury effects at the hippocampal-fornix level and nonspecific effects that disrupt cerebral connectivity and integration of neural networks responsible for memory.

\section{MATERIALS AND METHODS}

This study examined 86 MRIs from a group of TBI subjects $(M=58$, $\mathrm{F}=28)$ and 46 MRIs from a group of controls $(\mathrm{M}=31, \mathrm{~F}=15)$. All subjects were between the ages of 16 and $65 \mathrm{yr}$ (TBI, mean $=30.00$, s.D. $=11.73$; controls, mean $=37.21$, s.D. $=13.08$ ) Male/female subject ratios were matched for the two groups as one method of controlling for possible sex differences. All TBI subjects met diagnostic criterion for brain injury based on the TBI model systems criteria (Rosenthal and Harrison 1993) and control subjects were free from any previous head injury resulting in loss of consciousness; any central nervous system disease, including dementia or psychiatric illness; or history of alcohol or drug abuse.

Glasgow Coma Scores (GCS) for 62 of the 86 TBI subjects $(\mathrm{M}=40, \mathrm{~F}=22)$ were also obtained. The GSC scores ranged from 3 to 15 (mean $=8.4$, s.D. $=3.93$ ). All subjects were imaged at least two months postinjury, which has been shown to be sufficient time to show postinjury degenerative changes (Blatter et al. 1997).

MRI protocols were identical to previous research (Bigler et al. 1997; Blatter et al. 1997). Volumetric measures for the hippocampus were obtained in the coronal images, with a section thickness of $3 \mathrm{~mm}$. For the cross-sectional area of the fornix slice, image thickness was $5 \mathrm{~mm}$, with an intersection gap of $2 \mathrm{~mm}$.

The data were analyzed in the following three ways: The cross-sectional fornix area was analyzed using a single axial plane MRI slice for all 132 subjects. The fornix was identified in a single axial scan at its greatest width, using the head of the caudate nucleus (also at its greatest width) as a landmark (see Fig. 2). The fornix was then manually traced twice using the computer software IMAGE (Rasband 1993) and following criterion outlined in the Gale et al. study (1993). The average of the two measures was used to determine the mean cross-sectional area of the fornix for each subject. Hippocampal volumes were measured using Analyze (Biomedical Imaging Resource) based on methods previously reported (Bigler et al. 1997). All raters were reliable with at least an inter-rater and intra-rater coefficient of .91 .

Head size correction for hippocampal values was performed according to methods outlined previously (Bigler et al. 1997). However, the cross-sectional fornix size was very small, and further correction did not seem necessary because statistical

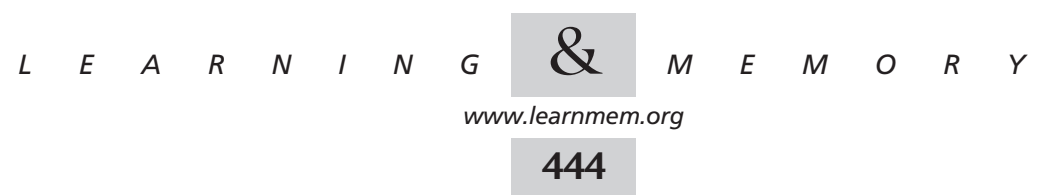


analysis demonstrated an almost unitary relationship between corrected and uncorrected fornix values $(r=0.905, P<0.0001)$ and a nonsignificant relationship between fornix size and head size $(r=0.10, P=0.13)$. Accordingly, no head size correction was made for fornix values and the reported means are actual estimates of cross-sectional area of the fornix at the level of the caudate.

The GMI score from the WMS-R, which is generally obtained around the time of imaging, was used as an overall index of memory in 57 of the TBI patients $(M=39, F=18)$ and has been shown to discriminate significantly between TBI subjects and normal controls (Wilhelm and Johnstone 1997). An analysis of variance (ANOVA) statistic was used to delineate the difference between the controls and the TBI patients. Additionally, the relationship between the hippocampus and the fornix measures for TBI and control subjects was analyzed using the Pearson's Product Moment correlation statistic.

TBI subjects were also divided into the following groups according to the severity of the initial injury as measured by GCS: a severe group (GCS $=3-8, n=35$ ) and a moderate-to-mild group (GCS $=9-15, n=27)$. The fornix area and hippocampal volume measures were compared for these two groups against the measures for the normal subjects using the multivariate Hotelling's Tstatistic, while controlling for sex and age factors. Finally, a Scheffe post hoc analysis was used to delineate any significant differences between the three groups.

The publication costs of this article were defrayed in part by payment of page charges. This article must therefore be hereby marked "advertisement" in accordance with 18 USC section 1734 solely to indicate this fact.

\section{REFERENCES}

Adams, J.H., Graham, D.I., and Gennarelli, T.A. 1985. Contemporary neuropathological considerations regarding brain damage in head injury. In Central Nervous System Trauma. Status Report-1985 (eds. D.P. Becker and J.T. Povlishock). National Institutes of Health, Washington, D.C.

Aggleton, J.P. 1999. Episodic memory, amnesia and the hippocampal-anterior thalamic axis. Behav. Brain Sci. 22: 425-489.

Bigler, E.D., Johnson, S.C., Anderson, C.V., Blatter, D.D., Gale, S.D., Russo, A.A., Ryser, D.K., Macnamara, S.E., Bailey, B.J., Hopkins, R.O., et al. 1996. Traumatic brain injury and memory: The role of hippocampal atrophy. Neuropsychol. 10: 333-342.

Bigler, E.D., Blatter, D.D., Anderson, C.V., Johnson, S.C., Gale, S.D., Hopkins, R.O., and Burnett, B. 1997. Hippocampal volume in normal aging and traumatic brain injury. Amer. J. Neuroradiol. 18: 11-23.

Blatter, D.D., Bigler, E.D., Gale, S.D., Johnson, S.C., Anderson, C.V., Burnett, B.M., Ryser, D., Macnamara, S.E., and Bailey, B.J. 1997. MR-based brain and cerebrospinal fluid measurement after traumatic brain injury: Correlation with neuropsychological outcome. Amer. J. Neuroradiol. 18: 1-10.

Blumbergs, P., Scott, G., Manavis, J., Wainright, H., Simpson, D., and McLean, A. 1994. Staining of amyloid precursor protein to study axonal damage in mild head injury. Lancet 344: 1055-1056.

Brodal, A. 1981. Neurological Anatomy in Relation to Clinical Medicine. 3rd ed. Oxford University Press, New York.

Carpenter, M.B. and Sutin, J. 1983. Human Neuroanatomy. 8th ed. Williams \& Wilkins, Baltimore, Maryland.

Chance, S.A., Highley, J.R., Esiri, M.M., Path, F.R.C., and Crow, T.J. 1999. Fiber content of the fornix in Schizophrenia: Lack of evidence for a primary limbic encephalopathy. Amer. J. Psych. 156: 1720-1724.
D'Esposito, M., Verfaellie, M., Alexander, M.P., and Katz, D.I. 1995. Amnesia following traumatic bilateral fornix transection. Neurology 45: 1546-1550.

Dixon, C.E., Taft, W.C., and Hayes, R.L. 1993. Mechanisms of mild traumatic brain injury. J. Head Traum. and Rehab. 8: 1-12.

Faden, A.I., Demediuk, P., Panter, S.S., and Vink, R. 1989. The role of excitatory amino acids and NMDA receptors in traumatic brain injury. Science 244: 798-800.

Fujita, T., Tanaka, T., Yonemasu, Y., Cendes, F. 1996. Electroclinical and pathological studies after parenteral administration of domoic acid in freely moving nonanesthetized rats: An animal model of excitotoxicity. J. Epilepsy 9: 87-93.

Fujita, T., Tanaka, T., Yonemasu, Y., Cendes, F., Cashman, N.R., and Andermann, F. 1996. Electroclinical and pathological studies after parenteral administration of domoic acid in freely moving nonanesthetized rats: An animal model of excitotoxicity. J. Epil. 9: 87-93.

Gale, S.D., Burr, R.B., Bigler, E.D., and Blatter, D. 1993. Fornix degeneration and memory in traumatic brain injury. Brain Res. Bull. 32: 345-349.

Gale, S.D., Johnson, S.C., Bigler, E.D., and Blatter, D.D. 1995. Nonspecific white matter degeneration following traumatic brain injury. $J$. International Neuropsychol. Soc. 1: 17-28.

Gean, A.D. 1994. Imaging of Head Trauma. Raven Press, New York.

Gennarelli, T.A., Thibault, L.E., and Graham, D.I. 1998. Diffuse axonal injury: An important form of traumatic brain damage. Neuroscientist 4: 202-215.

Heun, R., Mazanek, M., Atzor, K.R., Tintera, J., Gawehn, J., Burkart, M., Gaensicke, M., Falkai, P., and Stoeter, P. 1997. Amygdala-hippocampal atrophy and memory performance in dementia of Alzheimer type. Dement. Geriat. Cog. Disorders 8: 329-336.

Lencz, T., McCarthy, G., Bronen, R.A., Scott, T.M., Inserni, J.A., Sass, K J., Novelly, R.A., Kim, J.H., and Spencer, D.D. 1992. Quantitative magnetic resonance imaging in temporal lobe epilepsy: Relationship to neuropathology and neuropsychological function. Ann. Neurol. 31: 629-637.

Levin, H.S., Benton, A.L., and Grossman, R.G. 1982. Neurobehavioral Consequenses of Closed Head Injury. Oxford University Press, New York.

Martin, R.C., Hugg, J.W., Roth, D.L., Bilir, E., Gilliam, F.G., Faught, E., and Kuzniecky, R.I. 1999. MRI extrahippocampal volumes and visual memory: Correlations independent of MRI hippocampal volumes in temporal lobe epilepsy patients. J. Intl. Neuropsychol. Soc. 5: 540-548.

Nilsson, P., Hillered, L., Ponten, U., and Ungerstedt, U. 1990. Changes in cortical extracellular levels of energy-related metabolites and amino acids following concussive brain injury in rats. J. Cereb. Blood Flow Metabol. 10: 631-637.

Palmer, A.M., Marion, D.W., Botscheller, M.L., Swedlow, P.E., Styren, S.D., and DeKosky, S.T. 1993. Traumatic brain injury-induced excitotoxicity assessed in a controlled cortical impact model. J. Neurochem. 61: 2015-2024.

Pierce, J.E., Smith, D.H., Trojanowski, J.Q., and McIntosh, T.K. 1999. Enduring cognitive, neurobehavioral and histopathological changes persist for up to one year following severe experimental brain injury in rats. Neuroscience 87: 359-369.

Rasband, W. 1993. IMAGE (version 1.52). National Institutes of Health, Washington, D.C.

Shah, P.T., Yoon, K.-W., Xu, X.M., and Broder, L.D. 1997. Apoptosis mediates cell death following traumatic brain injury in rat hippocampal neurons. Neuroscience 79: 999-1004.

Squire, L.R., Weinberger, N.M., Lynch, G., and McGaugh, J.L. 1991. Memory: Organization and Locus of Change. Oxford Press, New York.

Stout, J.C., Bondi, M.W., Jernigan, T.L., Archibald, S.L., Delis, D.C., and Salmon, D.P. 1999. Regional cerebral volume loss associated with verbal learning and memory in dementia of the Alzheimer type. Neuropsychol. 13: 188-197.

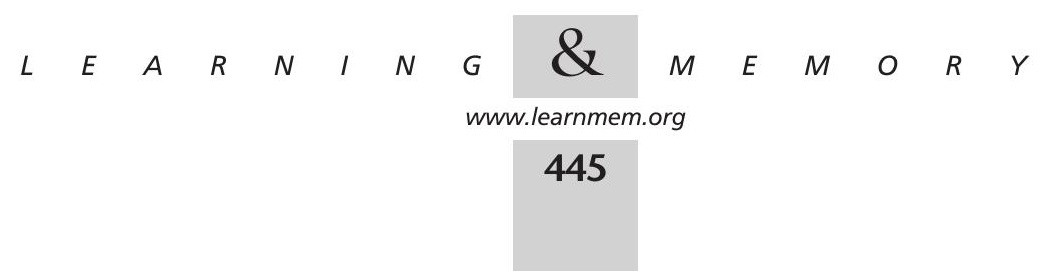


Strich, S.J. 1956. Diffuse degeneration of the cerebral white matter in severe dementia following head injury. J. Neurol. Neurosurg. Psych. 19: $163-185$

Sweeney, J.E. 1992. Nonimpact brain injury: Grounds for clinical study of the neuropsychological effects of acceleration forces. Clinical Neuropsychologist 6: 443-457.

Wechsler, D. 1987. Wechsler Memory Scale-Revised Manual. The Psychological Corporation, San Antonio, TX.

White, R.J. and Reynolds, I.J. 1996. Mitochondrial depolarization in glutamate-stimulated neurons: An early signal specific to excitotoxin exposure. J. Neurosci. 16: 5688-5690.

Wilhelm, K. L. and Johnstone, B. 1997. Use of the Wechsler Memory Scale-Revised in traumatic brain injury. Applied Neuropsychol. 2: $42-45$.

Received May 9, 2000; accepted in revised form September 8, 2000.

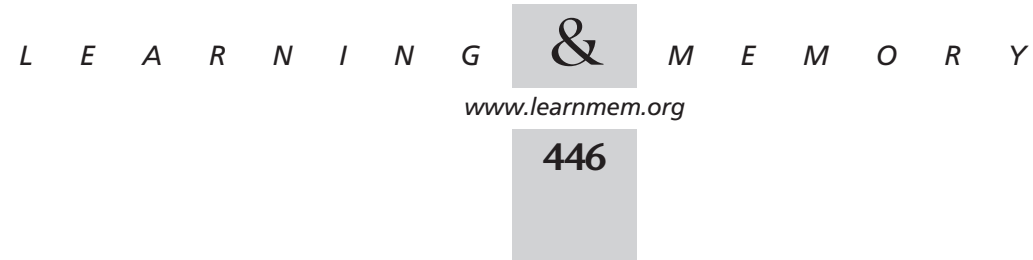




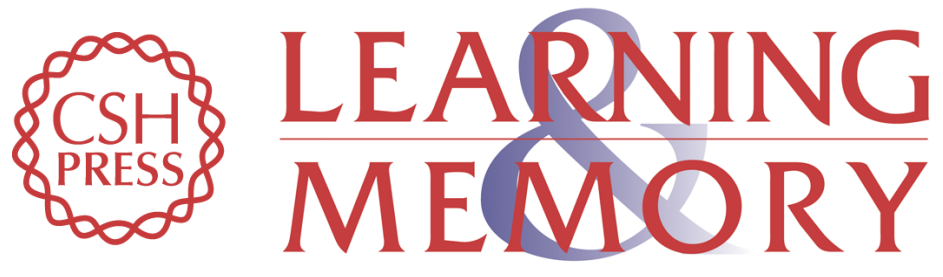

\section{Fornix and Hippocampal Atrophy in Traumatic Brain Injury}

David F. Tate and Erin D. Bigler

Learn. Mem. 2000, 7:

Access the most recent version at doi:10.1101/lm.33000

References This article cites 17 articles, 3 of which can be accessed free at: http://learnmem.cshlp.org/content/7/6/442.full.html\#ref-list-1

License

Email Alerting Receive free email alerts when new articles cite this article - sign up in the box at the Service top right corner of the article or click here. 